\title{
UJI KOMPETENSI PERAWAT DI INDONESIA
}

\author{
Masfuri \\ Fakultas IImu Keperawatan Universitas Indonesia, Jakarta \\ E-mail: masfuri@ui.ac.id
}

\begin{abstract}
ABSTRAK
Tujuan Penelitian: Artikel ini akan menjabarkan pencapaian uji kompetensi nasional keperawatan di Indonesia. Metode: Penelitian ini menggunakan data sekunder yang telah diterbitkan oleh panitia uji kompetensi nasional. Data secara keseluruhan yang diambil adalah periode ujian tahun 2015. Data disajikan secara deskriptif. Hasil: Pada tahun 2015, terdapat 66.687 Iulusan (Diploma III dan Profesi Ners) menjalani ujian, 35.892 (53,8 persen) dinyatakan lulus. Diskusi: Studi selanjutnya perlu lebih mengeksplor indikator kuat pada instansi pendidikan untuk meningkatkan presentasi keluluasan. Simpulan: Tingkat akreditasi memiliki hubungan kuat terhadap persentase kelulusan.
\end{abstract}

Kata Kunci: uji kompetensi nasional, keperawatan.

\section{ABSTRACT}

Objective: This article will describe the achievement of the national examination in nursing education in Indonesia. Methods: This study employed secondary data published widely by the national examination committee. Data were taken from the 2015 examination. Data were presented descriptively. Results: In 2015, there were 66,687 graduates of Diploma III and Professional Nurse who took examination, $53.8 \%$ of them $(35,892)$ passed. Discussion: Further study is needed to explore the strong indicator in educational institutions to improve the passing percentage. Conclusion: Level of accreditation has strong correlation with the passing percentage.

Keywords: national examination competency, nursing.

\section{LATAR BELAKANG}

Perawat adalah salah satu unsur strategis tenaga kesehatan di setiap tatanan pelayanan kesehatan. Resolusi World Health Assembly (WHA) Nomor 54.12 Tahun 2001 tentang penguatan peran perawat dan bidan menyebutkan bahwa kontribusi perawat dapat menurunkan angka morbiditas, mortalitas, dan disabilitas serta meningkatkan gaya hidup sehat masyarakat. Di banyak negara Asia, seperti Indonesia, potensi strategis terebut tidak selamanya dapat dipenuhi karena berbagai keadaan seperti kondisi kerja dan kurangnya relevansi kompetensi perawat dengan kebutuhan masyarakat (World Health OrganizationSouth East Asia Region, 2003).

Perawat memiliki tugas 24 jam sehari dan 7 hari dalam seminggu. Berbagai kejadian penting hingga penyelamatan jiwa dapat diantisipasi, seperti early warning sign, monitoring tanda vital, perkembangan pasien, adaptasi pasien dengan penyakitnya. Semua hal tersebut adalah tanggung jawab perawat. America Health Research and Quality (2010) menyatakan bahwa perawat bertanggung jawab terhadap length of stay di rumah sakit. Needleman dan Hasmiller (2011) sangat percaya bahwa length of stay adalah cermin dari kualitas, efesiensi, dan 
efektivitas asuhan keperawatan. Sebagai sebuah contoh, pneumonia didapat pasien di ruang perawatan intensive akibat kurangnya kompetensi perawat akan meningkatkan biaya perawatan sebesar 80 persen (AHRQ, 2010). Meta-analisis yang dilakukan oleh Agency for Healthcare Research and Quality (AHRQ) tahun 2007 dan meta-analisis lain hingga sekarang konsisten bahwa jumlah staf keperawatan (RN) terstandar yang cukup (dibanding jenis tenaga keperawatan yang lebih rendah, tidak terstandar) memiliki asosiasi kuat dengan rendahnya angka kematian, kegagalan penyelamatan, henti jantung, pneumonia didapat di rumah sakit, dan kejadian yang tidak dikehendaki. Potensi besar tersebut ternyata banyak terhalang oleh berbagai faktor, seperti kualitas pendidikan yang belum terstandar, program penerimaan staf baru tanpa orientasi tugas yang jelas, standar kondisi kerja yang memprihatinkan, dan ikatan kerja yang tidak jelas. Untuk itu, salah satu upaya perbaikan adalah dengan penyelenggaraan uji kompetensi secara nasional.

Uji kompetensi nasional adalah alat penapis (screening) untuk mengidentifikasi calon perawat yang memiliki cukup kemampuan memasuki dunia praktik keperawatan (Fulcher dan Mullin, 2011) dan menjalanan peran secara efektif sebagai perawat baru (National Council of State Board of Nursing, 2013). Uji kompetensi nasional adalah alat untuk memberi keputusan pemberian lisensi perawat. Uji kompetensi nasional harus secara psychometric benar dan konsisten dengan praktik keperawatan terkini (Fulcher dan Mullin, 2011). Hasil uji kompetensi nasional dapat dijadikan elemen penting dalam transformasi kurikulum pendidikan. Di Taiwan, mahasiswa yang memiliki indeks prestasi kumulatif yang baik cenderung memiliki potensi kelulusan yang tinggi dalam uji lisensi nasional (Lin, 2003). Di Oklahoma, ada sekolah yang memiliki nilai kelulusan National Council of Licensure Examination (NCLEX) di bawah angka nasional disebabkan adanya tekanan untuk memenuhi jumlah mahasiswa dan tidak memiliki waktu mempersiapkan NCLEX bagi mahasiswanya (Laing-Arie, 2003).

\section{METODE}

Penelitian ini menggunakan data sekunder yang telah diterbitkan oleh panitia uji kompetensi nasional. Data secara keseluruhan diambil untuk periode ujian tahun 2015. Data akreditasi diambil dari laman lembaga akreditasi dan badan akreditasi nasional sampai dengan Oktober 2015. Data disajikan secara deskriptif.

HASIL

Uji kompetensi nasional dilakukan dua kali dalam setahun. Bulan penyelenggaraannya masih berubahubah, tetapi antara bulan Maret-Mei dan September-November. Jumlah total peserta yang mengikuti ujian pada tahun 2015 adalah 66.687 peserta dari 1.179 institusi pendidikan keperawatan (Tabel 1). 
Tabel 1 Jumlah Institusi dan Peserta Uji Kompetensi DIII Keperawatan dan Profesi Ners Periode I dan II Tahun 2015

\begin{tabular}{lccc}
\hline \multirow{2}{*}{ Program Studi } & \multicolumn{2}{c}{ Periode Ujian 2015 } & \multirow{2}{*}{ Jumlah } \\
\cline { 2 - 3 } & Pertama & Kedua & \\
\hline Keperawatan & 372 & & 800 \\
- Jumlah Institusi & 11.131 & 328 & 44.999 \\
- Jumlah peserta & 3.283 & 21.803 & 25.086 \\
- Jumlah Lulus & $29,49 \%$ & $64,38 \%$ & \\
- Persentase Lulus & 177 & & 379 \\
\hline Ners & 10.053 & 202 & 21.688 \\
- Jumlah Institusi & 4.569 & 11.635 & 10.806 \\
- Jumlah peserta & $45,45 \%$ & 6.237 & \\
- Jumlah Lulus & & $53,61 \%$ & \\
- Persentase Lulus & & & \\
\hline
\end{tabular}

Data peserta adalah peserta yang hadir dalam ujian, bukan peserta yang mendaftar. Jumlah ujian periode pertama untuk program Diploma III (DIII) cenderung lebih kecil, tetapi jumlah peserta profesi relatif stabil. Secara umum, periode pertama lebih banyak diikuti oleh peserta yang tidak lulus pada periode kedua tahun sebelumnya dan program studi yang kelulusannya relatif lebih lambat daripada program studi keperawatan secara umum. Ujian dilakukan di 109 dan 203 tempat uji kompetensi untuk program DIII, sementara untuk program profesi dilakukan di 51 dan 56 tempat uji kompetensi.

Berikut ini disajikan data persentase kelulusan berdasarkan wilayah Kopertis (Koordinator Perguruan Tinggi Swasta), perguran tinggi negeri dan tipe akreditasi (Grafik 1). Namun sayang, karena keterbatasan data, hanya Program Studi Ners yang cukup layak dipresentasikan.

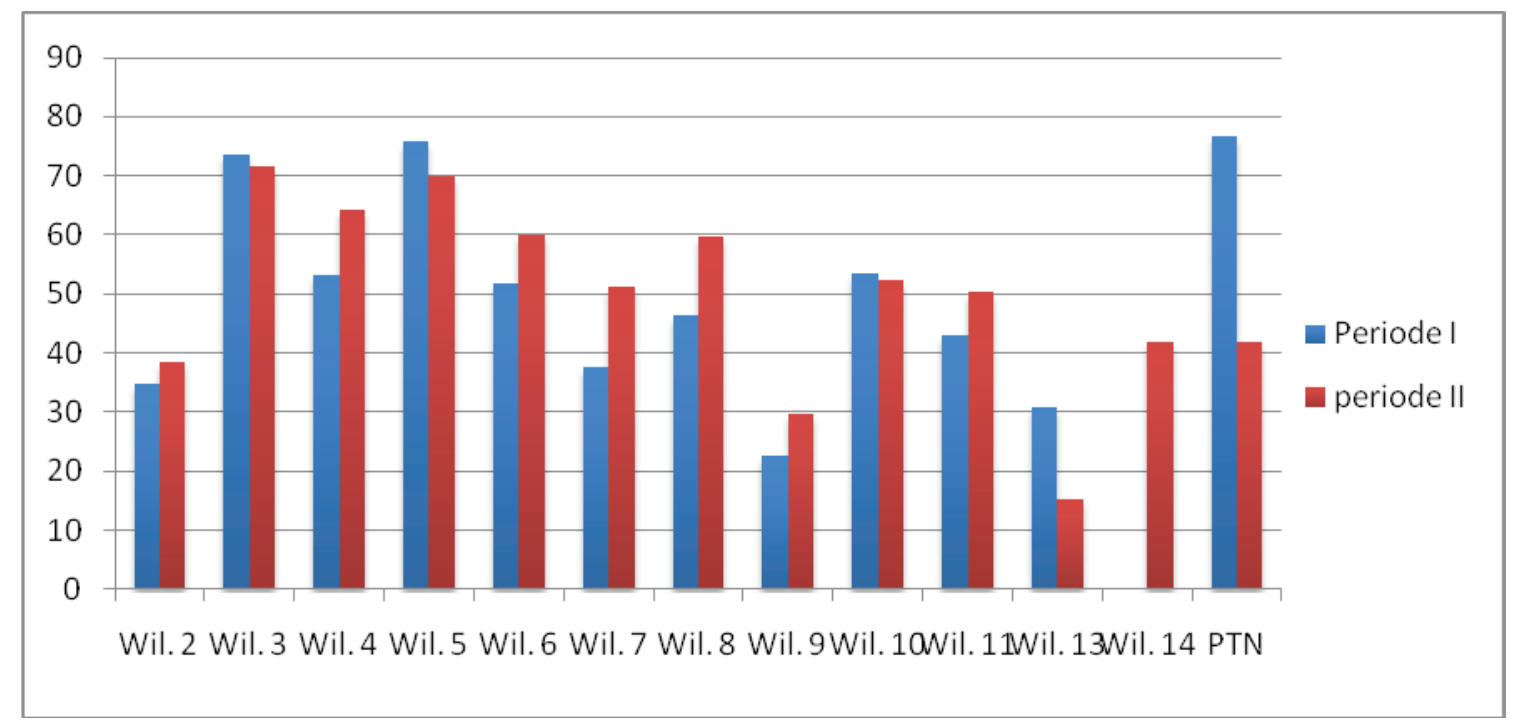

Grafik 1 Sebaran Persentase Kelulusan Program Studi Ners Tiap Wilayah Kopertis dan PTN 
Tingkat kelulusan tertinggi pada tinggi adalah Kopertis 3 dan 5. Sementara periode I ada pada PTN, tetapi turun pada itu, wilayah yang relatif stabil rendah adalah periode II. Wilayah Kopertis yang relatif stabil Kopertis 9 dan 13.

Tabel 2 Kelulusan Berdasarkan Status Akreditasi Program Profesi Ners

\begin{tabular}{ccccccccc}
\hline Akreditasi & \multicolumn{4}{c}{ Periode I } & \multicolumn{4}{c}{ Periode II } \\
\cline { 2 - 10 } & $\begin{array}{c}\text { Jumlah } \\
\text { institusi }\end{array}$ & $\begin{array}{c}\text { Jumlah } \\
\text { Peserta }\end{array}$ & $\begin{array}{c}\text { Jumlah } \\
\text { Lulus }\end{array}$ & $\begin{array}{c}\text { Persentase } \\
\text { Lulus }\end{array}$ & $\begin{array}{c}\text { Jumlah } \\
\text { institusi }\end{array}$ & $\begin{array}{c}\text { Jumlah } \\
\text { Peserta }\end{array}$ & $\begin{array}{c}\text { Jumlah } \\
\text { Lulus }\end{array}$ & $\begin{array}{c}\text { Persentase } \\
\text { Lulus }\end{array}$ \\
\hline A & 6 & 361 & 299 & 82.83 & 6 & 348 & 302 & 86.78161 \\
\hline B & 35 & 1635 & 1045 & 63.91 & 34 & 2099 & 1515 & 72.17723 \\
\hline C & 136 & 8057 & 3225 & 40.03 & 162 & 9188 & 4429 & 48.20418 \\
\hline
\end{tabular}

Akreditasi A memiliki kelulusan yang stabil dan lebih tinggi pada periode I dan II. Sementara itu, akreditasi B berada di bawahnya diikuti oleh akreditasi $C$. Penyumbang peserta tertinggi berada pada akreditasi C. Namun, peserta dari akreditasi A hanya di bawah 10 persen dari akrediasi $C$ karena jumlah institusinya lebih sedikit.

\section{DISKUSI}

Uji kompetensi pertama dilakukan pada tahun 2013 untuk lulusan pendidikan baru perawat DIII dan Profesi Ners. Tahun 2015 adalah tahun ketiga. Dari data tahun lalu, terlihat bahwa tingkat kelulusan masih fluktuatif dan untuk ners cenderung stabil dibandingkan dengan DIII. Waktu mengerjakan satu soal satu menit, sama dengan New Zealand (Dearnaly, 2014) dan beberapa negara lain. Meskipun demikian, jumlah soal dan metode pemberian ujian berbeda-beda.

Di Taiwan, mahasiswa yang memiliki indek prestasi kumulatif yang baik cenderung memiliki potensi kelulusan yang tinggi dalam uji lisensi nasional (Lin, dkk, 2003). Di Oklahoma, sekolah yang memiliki nilai kelulusan NCLEX di bawah angka nasional disebabkan adanya tekanan untuk memenuhi jumlah mahasiswa dan tidak memiliki waktu mempersiapkan NCLEX bagi mahasiswanya (Laing-arie, dkk, 2003). Tingkat kelulusan yang tinggi dari sekolah bisa juga disebabkan bahwa calon peserta yang dianggap belum siap tidak didaftarkan ujian nasional (National League of Nursing, 2012). Tingkat kelulusan di Indonesa tidak jauh berbeda dengan survei kualitas pendidikan keperawatan dan kebidanan di Indonesia tahun 2012 yang dilakukan kerja sama antara Kementerian Kesehatan dan World Health Organization (WHO) Indonesia. Dalam survei tersebut diketahui bahwa tingkat kedalaman materi yang diajarkan dan metode pengajaran agar mahasiswa memahami materi esensial asuhan keperawatan yang cukup baik baru dilakukan oleh 45 persen institusi pendidikan dan capaian target kompetensi klinik esensial yang baik baru mencapai 30 persen (Masfuri dan Haroen, 2012).

Persentase lulusan tidak berbeda jauh dengan survei yang dilakukan oleh WHO tahun 2012 tentang kualitas pendidikan keperawatan dan kebidanan. Tampak bahwa dalam berbagai wilayah, tingkat kelulusanya berbeda. Hal yang sama juga dialami dalam tes NCLEX. Terdapat perbedaan tingkat kelulusan antara kulit putih dan bukan kulit putih. Hal ini dimungkinkan ada faktor lain yang berpengaruh, seperti tingkat kemampuan baca dan pemahaman bahasa di samping faktor kesiapan akademik yang rendah (NLN, 2012). Legislative Analyst Offcice (LAO) California (2007) meyakini bahwa institusi pendidikan dengan tingkat kelulusan ujian nasional yang tinggi adalah 
cermin dari dukungan yang lebih baik dalam semua proses belajar mahasiswa. Hal ini sesuai dengan tingkatan akreditasi yang lebih tinggi memiliki kecenderungan tingkat kelulusan yang lebih baik. Seperti juga akreditas dapat menjadi kebanggaan bagi institusi dan mahasiswa atau lulusan, menurut McGahee, dkk (2010) tingkat kelulusan ujian nasional juga menjadi kebanggaan bagi institusi dan Iulusan. Begitu pentingnya akreditasi nasional, NCSBN (National Council of State Board of Nursing) (2014) memiliki target pada tahun 2020, 95 persen bachelor of nursing program di Amerika Serikat harus diakreditasi secara nasional karena saat ini akreditasi banyak dilakukan oleh negara bagian. Sangat terlihat perbedaan kelulusan antarwilayah Kopertis dan perguruan tinggi negeri serta tingkat akreditasi institusi pendidikan.

Assessment memiliki peran penting dalam proses belajar mahasiswa dan kecenderungan tingkat kelulusan dapat dijadikan dasar evaluasi kurikulum. (McGahee, dkk, 2010). Hal ini diharapkan dapat meningkatkan kualitas lingkungan pendidikan yang sejalan dengan kurikulum (Ramsden, 2003). Tingkat kelulusan ujian lisensi dapat dijadikan perspektif untuk meningkatkan proses pendidikan atau implementasi kurikulum (Pennington dan Spurlock, 2010). Institusi pendidikan memiliki berbagai cara dan usaha untuk memprediksi tingkat kesuksesan ujian nasional selama proses pendidikan (Grossbach dan Kuncel, 2014)

\section{SIMPULAN}

Uji kompetensi nasional telah berlangsung sejak tahun 2013 untuk pendidikan keperawatan dengan tingkat kelulusan yang masih belum merata di seluruh Indonesia. Hanya perguruan tinggi di 5 wilayah Kopertis pada tahun 2015 yang memiliki tingkat kelulusan di atas 50 persen.
Status akreditasi terlihat memiliki pengaruh yang baik bagi tingkat kelulusan.

Mengingat lembaga akreditasi memiliki kecepatan gerak yang terbatas, diperlukan penelitian lebih lanjut untuk mencari predictor terhadap tingkat kelulusan uji kompetensi nasional yang dapat diajukan sebagai salah satu upaya perbaikan institusi pendidikan. Perlu dipertimbangkan penerapan sistem kuota berdasarkan tingkat akreditasi di samping pertimbangan daya serap kerja lulusannya.

\section{DAFTAR PUSTAKA}

AHRQ. (2010). "Nurses and Quality of Care". http://archive.ahrq.gov/downloads/pub/ evidence/pdf /nursestaff/nursestaff.pdf.

Dearnaly, M. (2014). English Language Test: No Extra time. New Zealand Herald. (APN New Zealand Limited).

Direktorat Jenderal Pendidikan Tinggi. (2015). "Registrasi Uji Kompetensi Nasional Profesi Ners". www.ukners. dikti.go.id.

Fulcher, R dan Mullin, C. M. (2011, March). A Data-Driven Examination of the Impact of Associate and Bachelor's Degree Programs on the Nation's Nursing Workforce (Policy Brief 2011-02PBL). Washington, D.C.: American Association of Community Colleges.

Grossbach, A. dan Kuncel, N., R. (2011). "The Predictive Validity of Nursing Admission Measures for Performance on the National Council Licensure Examination: A Meta-Analysis". Journal of Professional Nursing. 27 (2).

Laing-arie, P., Ludlow, C., Yates, A., Blanke, D., Ed, D., dan Michael, L. (2003). NCLEX Pass Rate Task Force Report and Recommendations, 73106(405). Oklahoma Board of Nursing.

Lin, R.S.J., Fung, B.K.P., Hsiao, J.K., dan Lo, H.F. (2003). "Relationship between Academic Scores and Performance 
on National Qualified Examination for Registered Professional Nurses (NQEXRPN)". Nurse Education Today, 23, hlm.: 492-497. doi:10.1016/S02606917(03)00073-X

LAO. (2007). "Ensuring an adequate health workforce: Improving State Nursing Programs." Online: available at http://www.lao.ca.gov/2007/nursing/ nursing_052907.aspx

Masfuri, M. dan Haroen, H. (2013). "Quality of Nursing and Midwifey Education in Indonesia". Proceeeding of Socialization Pre Service Nursing and Midwifery Education Study Survey Conference. Jakarta, 23 January 2013.

McGahee, T.W., Gramling, L., dan Reid, T.F. (2010). "NCLEX-RN® Success: Are There Predictors". Southern Journal of Nursing Research. 10(4). Online, available at http://www.resourcenter.net/images/snrs/ files/sojnr_articles2/vol10num04art13. html.

Nedleman, J. dan Hasmiller. S (2011). "The Role of Nurse in Improving Hospital
Quality". http://www.healthpolicyfellows. org/pdfs/TheRoleOfNursesInImprovi ngHospitalQualityandEfficiency-RealWorldResultsbyNeedlemanandHassmi. pdf .

NLN. (2012). "The Fair Testing Imperative in Nursing Education". http://www.nln. org/docs/default-source/about/nln-visionseries-(position-statements)/nlnvision_4. pdf.

NCSBN. (2013). “Annual Report 2013”. www. ncsbn.org.

Pennington, T.D. dan Spurlock D. (2010) "A systematic review of the effectiveness of remediation interventions to Improve NCLEX-RN Pass Rates". Journal of Nursing Education. 49(9), hlm.: 485-92. doi: 10.3928/01484834-20100630-05.

Ramsden, P. (2003). Learning to Teach in Higher Education. (2 ${ }^{\text {nd }}$ Edition). London and New York: Routledge Falmer.

WHO-SEARO (2003). Nursing and Midwifery Workforce Management: Conceptual Framework. New Delhi: SEARO Publication. 